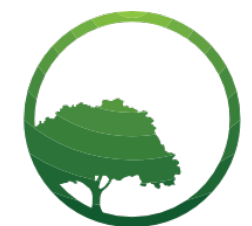

Business \& Social Science IJRBS

\section{Research in Business \& Social Science}

IJRBS Vol 6 No 4, ISSN: 2147-4478

Contents available at www.ssbfnet.com/ojs

http://dx.doi.org/10.20525/ijrbs.v6i4.760

\title{
Comparisons of Website Visit Behavior between Purchase Outcomes and Product Categories
}

\section{Chatpong Tangmanee}

Chulalongkorn Business School, Chulalongkorn University, Bangkok 10330, Thailand

Corresponding Author

\begin{abstract}
The online retail business has grown substantially. Given distinctive product categories (e.g. search or experience goods), owners must put an effort in the design of websites so every visit may end with a purchase. Clickstream panel data allowing examination into website visiting behavior (i.e. the number of pages viewed (or pageview) or the visit duration) are increasingly accessible. However, it is unclear whether the differences of the two visiting behavior between purchase outcome or product categories are significant. The present study hopes to fill the void. An analysis of 27,528 visit sessions extracted from ComScore verifies that (1) the difference of page views between purchase outcomes and that between product categories were significant and (2) only the difference of visit duration between the product categories was significant but that between purchase outcomes was insignificant. In addition to theoretical insight into online behavior across purchasing horizons and product categories using clickstream data, online retail practitioners could apply the findings to enhance the possibility of the purchases at their online stores.
\end{abstract}

Key words: Website Visit Behavior; Purchase Outcomes; Product Categories

JEL classification: C51, M15, M31

\section{Introduction}

Electronic commerce has grown significantly and so has online retail businesses. It is predicted that online retail sales will reach US $\$ 370$ billion by 2017 (Gustafson, 2017). The number of online retail stores may also verify its exponential growth (Baird, 2017). In 2016, Amazon was ranked the number one shopping website across 59 countries and could claim over $20 \%$ of the traffic for the shopping category of websites (Similarweb, 2016). In 2016, VictoriasSecret.com was among the top online retail websites in America. A single visitor spent an approximately 6.46 minutes to view about 6.24 pages; whereas a visitor at Drugstore.com spent around 2.0 minutes for 1.8 pages on average. 
Moreover, a number of governments have set a national agenda to promote online businesses in order to boost their national economy. The government of Thailand, for example, has launched the Thailand 4.0 project in which online retail businesses receive remarkable attention from the government and practitioners.

Despite the great effort in promoting online businesses, a large proportion of website visits still end without a purchase (Lin, et al., 2010;). Logically, the longer visitors stay, the more likely the purchase would be. Also, should visitors continue observing content on many web pages, they would learn a large amount of detail and could finally make a purchase at the end of the visit. It indicates the importance of an individual's website visiting behavior. The significance is increasingly pronounced in the context of online retail businesses. In other words, if a visitor stays long enough at an e-commerce website or if he visits a sufficient number of web pages, he should be inclined to make a purchase.

Previous work has attempted to confirm the connection among visiting and purchasing behaviors (Lin, et al., 2010; Mallapragada, et al., 2016). The findings are promising; however, they are inconclusive. In fact, a fair number of e-commerce scholars have remarked on the relationship between the visiting behavior and the purchase outcome in that it depends on what the product is. In 2008, the review of books at Amazon is significantly related to its sales volume (Kousha \& Thelwall, 2014). Lin, et al., (2010) confirmed the difference in the relationships between two types of products (e.g., search and experience goods). Using an experimental approach, Sunikka, et al. (2011) discovered that the online banking products on a webpage in which a customer could look for all product information received more benefits from the incentives offered together on the website than those products with little information; the purchase must then rely on other sources of information. Based on the econometric approach, Panagiotelis, et al., (2013) acknowledge the effect of different online product types on the sale volume occurring in online retail websites. Using a random effect model, Danaher, et al. (2006) found that the visit duration is a function of visitors' demographics, website characteristics and repeated visits. For instance, older visitors relatively enjoy advertisement on a website which results in a longer visit.

Given the unclear connection among website visiting behavior, purchase outcomes and product categories, the current study attempted to achieve the following objectives: We attempt to compare the visit duration between purchase outcomes and product categories and to compare the number of web pages viewed (or hereafter called pageviews) between purchase outcomes and product categories.

\section{Literature Review}

An immense number of e-commerce websites have worked to improve their appearance in order to attract more visitors. Not only do they want a large number of visitors, they also prefer the guests to view many web pages and to have a long visit on their websites. The longer they stay, the more likely they could be to make a purchase. Amazon, for example, is able to offer effective recommendations to visitors based only on their behavior during the visit at the website (Mallapragada, et al., 2016). In 2016, Ticketmaster was ranked high in the list of online retail websites with an average pageview per visitor of 6.24. A single visitor spent an average of 6.46 minutes on Ticketmaster (Alexa, 2017). Also, Apple relies on visiting behavior in order to craft its content so that visitors enjoy the visit and perhaps purchase a few items (Panagiotelis, et al., 2013). Insight into visiting behavior is therefore crucial. However, which specific behavior to observe remains a question, not to mention how to observe it properly.

Accepted in previous research, stickiness behaviors are indicative of website visitors (or customers if they had already made the purchase) clinging onto the website, thereby increasing the chance of purchase (Lin, et al., 2010; Mallapragada, et al., 2016). Among stickiness behavior, a pageview and visit duration have received much research attention (Ray, et al., 2004; Huang, 2015; Xun, 2015; Lin, et al., 2010). A common visit to an e-commerce website includes multiple pages during which a visitor acquires certain information before making a purchase. A visit to a website is described as a session which starts when a visitor goes to a specific site and ends when he either leaves the website or closes the browser tab or window. A pageview and visit duration are among important outcomes of a visit to an online retail website (Mallapragada, et al., 2016; Panagiotelis, et al., 2013). A pageview refers to the number of web pages a visitor has visited in one session whereas duration is the amount of time for which the visitor stays for one session. Both of them are 
often used to indicate one's stickiness to an online website (Lin, et al., 2010). It should be clear that both pageviews and duration in the present study are the session-based variables. Stickiness may be perceived as a visitor's series of visits to the same website (Huang, 2015; Claase, et al., 2014). While fairly significant, it describes a concept different from the stickiness referred to in this study. In fact, the proper label for the stickiness as series of visits to the same website would have been continued (or repeated) visits (Ray, et al., 2014).

Researchers have long examined the connection among pageviews, visit durations, and purchase outcomes (i.e., whether or not visitors made a purchase within their visit session). Using a data stream, Lin, et al., (2010) confirmed that a pageview is significantly indicative of visitors' likelihood of a purchase. With a similar approach, Mallapragada, et al., (2016) discovered the negative relationship between pageviews and basket value. Similar findings were also found by Panagotelis, et al. (2013).

The number of web pages viewed during a typical session was also examined in much research but for different purposes. For example, a pageview was incorporated in a data-mining project in order to enhance the recommendation at an online retail store (Yan \& Li, 2006). The pageview was also adopted to signify a visitor's attention given to initial public offering (IPO) pricing and its effect on the pricing was significant in both American and Japanese markets (Okada \& Takahashi, 2015). In an attempt to develop and verify the typology of online shopping strategies, Moe (2003) proposed two types of purchasing horizons (e.g., purchase within a visit session or possible purchase in the future) and found the connection between these types of purchases and the pageviews.

In addition to the pageviews, a visit duration has been investigated in the online retail context. Basically, the duration is related to the outcomes. Danaher, et al. (2006) raised three reasons that visit duration is important. First, visit duration prolongs exposure to online advertising. The longer the stay is, the higher the recollection of the advertising message. Second, long duration signifies a visitor's interest, thereby enhancing the chance of an online purchase. This was made evident by Moe and Fader (2004). Third, a longer duration implies a higher value of the company. Moreover, Lin (2007) confirmed through her survey that longer duration significantly led to higher purchasing. The major drawback in her paper is that she operated the two constructs as visitors' intent to stay and their intent to purchase. The utility of her findings could have been wider had the two variables been the actual observation (e.g., the actual length) of visit or an actual purchase. Using actual data at one online retail store, Olbrich and Holsing (2011) verified that a customer's duration (or viewtime, in their words) related to the decision to purchase as indicated by a click on the checkout button.

An increasing number of research projects have acknowledged the use of clickstream data (Bucklin, et al., 2002; Xun, 2015; Montgomery, et al., 2004; Moe \& Fader, 2004). Bucklin, et al. (2002) addressed the importance of clickstream data and suggested how researchers could benefit from using the clickstream data, especially in regards to how they can be used to examine online customers' choices. Based on these datasets, researchers have confirmed the association between visit duration and purchase outcomes. According to Lin, et al., (2010), the longer they stay, the higher the chance of purchase. Such relationship is however less significant when compared to the connection between the pageviews and the chance of online purchasing (Lin, et al., 2010). In the context of mobile retail shopping, Kim, et al., (2015) tested the effect of website stickiness on the online word-of-mouth. Whether a purchase is made was, however, excluded from their study. Mallapragada, et al., (2016) also successfully tested the effect of visit duration, in addition to that of pageviews, on the value of the purchase. However, the comparison of pageviews between purchasers and non-purchasers by Lin, et al. (2010) was not significant. Moe (2003) remarked the possible difference of pageviews and duration among visitors who come to retail websites by search goods and by experience goods.

Although a sizable amount of research has addressed two stickiness constructs (i.e., a pageview and a visit duration), only few have validated their correlation with the purchasing choice (i.e. whether the purchase is made). As a result, the first two hypotheses in response to the study's first objectives are: 
$\mathrm{H} 1$ : The number of pageviews is significantly different between the sessions where the purchase is made and those where it is not made; and

$\mathrm{H} 2$ : The visit duration is significantly different between the sessions where the purchase is made and those where it is not made.

Not only does website visiting behavior relate to the purchase choice, it also depends on what products are offered on the website. Customers of some products may be able to assess a sufficient amount of information prior to making a purchase while others may find it difficult to consider all the details and the purchase may be based on other factors including one's encounter with the product. The former is known as search goods and the latter is experience goods (Moe, 2003; Sunikka, et al., 2011; Montgomery, et al., 2014). Examples of search goods include books, videos, and music CDs, while clothing and perfume are considered experience goods.

Using a salesperson as a metaphor, Moe (2003) classified online shoppers into four groups, one of which seem related to those who enjoy search goods. They are the knowledge builders who prefer to evaluate a large chuck of information on all aspects of the products and could later make a purchase. Using an experiment, Sunikka, et al. (2011) confirmed that online banking customers prefer search goods as a promotional item to the experience ones. Since it was offered as a promotion for online financial services, the customers would like to assess all details before continuing with the services. In addition, Sunikka, et al. (2011) discovered the significant difference of pageviews and visit duration between two types of the promotional items. Similar findings were also explained by Lin, et al., (2010). Moe (2003) remarked the possible difference of pageviews and duration among the visitors who come by retail websites of search and of experience goods. In addition to addressing the two types of goods during visit sessions to retail websites and noting the significant impact of different product categories on pageviews and duration, Mallapragada, et al., (2014) adopted a different typology of the product. Nonetheless, their work has emphasized the importance of various product categories and their involvement in the number of webpages viewed and the visit duration. Montgomery, et al. (2004) also recognizes the significance of product categories in explaining a visit path in an online book seller.

To recapitulate, previous work has acknowledged the magnitude of product categories on pageviews and visit duration. However, the examination on their connection yields indecisive findings, suggesting additional empirical work. Consequently, the final two hypotheses in response to the study's second objective are:

$\mathrm{H} 3$ : The number of pageviews is significantly different between the sessions on websites of search goods and the sessions on those of experience goods; and

H4: The visit duration is significantly different between the sessions on websites of search goods and the sessions on those of experience goods.

In general, visitors who have a long session at an e-commerce website are more likely to purchase items than those with a short visit. Similarly, those visitors who move around in a website, hopping through a series of webpages, may spend more money at the website than those who visit only a few pages. The relationship between the pageview and the visit duration has been examined in a fair number of projects. Given the correlation of both pageview and duration to the incidence of purchase, Lin, et al. (2010) claimed without clear empirical evidence the connection between the pageview and the visit duration. Driving upon the conversion in online retail websites, Olbrich and Holsing (2011) remarked on the possible relationship between the two variables. Examining the use of the pageview and the duration to predict the probability of purchase, positive correlation between the two variables was claimed by Mallapragada, et al. (2016).

Despite of previous research speculating the relationship between the pageview and the visit duration in the context of online retail business, virtually none has empirically tested whether both are related. Consequently, a third hypothesis is:

H5: The pageview and the visit duration are significantly related. 


\section{Research Methodology}

\section{Data Preparation}

To respond to the study's objectives and five hypotheses, we obtained transaction-level household panel data from the ComScore Web Behavior Panel for 2015. The panel data include visiting behavior from which we were able to extract all variables we needed in order to respond to our objectives. Given the ComScore subscription, we were able to extract a large amount of visiting behavior to various retail websites and to record the sites visited, session duration, and the number of web pages viewed. From the total number of households in ComScore, we selected data on five online retail websites. The three websites selling search goods are Amazon, Drugstore, and Ticketmaster and those offering experience ones are Landsend, and VictoriasSecret. The selection was based on recommendations by Lin, et al. (2010) and available data at ComScore. We then removed the sessions that had a visit duration of less than 30 seconds. Such a short stay might indicate an accidental visit, resulting in 27,528 sessions for further analyses.

\section{Data Analysis}

In addition to the descriptive statistics describing all major constructs, we adopted the proportional $Z$ test to verify if the difference of pageviews and that of visit durations between two purchase outcomes and between product categories are statistically significant. To validate the significance of the correlation between the pageview and visit duration, we adopted the Pearson's r-correlation analysis technique.

\section{Results}

Tables 1 and 2 present descriptive statistics of pageviews and visit duration, categorized by purchase outcome and product categories. In Table 1, about $95 \%$ of all sessions from which we collected data yielded the purchase. The high conversion rate could be a result from the selection of five well-established online retail websites. Among the sessions with purchase, the largest proportion (93\%) was from Amazon and the smallest (1\%) from Landsend. We obtained 1,197 sessions with no purchase only from Amazon (see Table $3)$.

Table 1: Descriptive statistics of pageviews and duration categorized by purchase outcomes

\begin{tabular}{|l|c|c|c|c|c|}
\hline Purchase outcomes & Visiting sessions & \multicolumn{2}{|c|}{ Pageviews } & \multicolumn{2}{c|}{ Duration } \\
\hline & & Mean & Standard deviation & Mean & Standard deviation \\
\hline Completed & 26,331 & 35.1 & 27.8 & 29.4 & 28.9 \\
\hline Not completed & 1,197 & 39.6 & 28.9 & 29.8 & 28.0 \\
\hline Total & 27,528 & 35.3 & 27.9 & 29.5 & 28.8 \\
\hline
\end{tabular}

In Table 2, about $5 \%$ of all sessions were from experience goods and the remaining from search goods. Among the sessions from websites selling search items, the largest proportion (98\%) was from Amazon whereas the largest one (70\%) from experience items was from VictoriasSecret (see Table 4). As shown in Table 1, the pageviews on the non-completed purchasing sessions were higher than those on the completed ones. The findings on the visit duration are much the same. The independent t-test confirmed the significant difference of the pageviews between the two purchase outcomes $(t=-5.183, p$-value $=.000)$. However, the difference of the visit duration is not significant $(t=-0.424$, $p$-value $=.602)$. Regarding the difference of pageviews and that of visit duration between two product categories, the independent t-test confirmed the significant difference in both cases (for the pageviews, $t=-7.121, p$-value $=.000$; and for the duration, $t=$ 4.194, $\mathrm{p}$-value $=.000$ ).

Table 2: Descriptive statistics of pageviews and duration categorized by product categories

\begin{tabular}{|l|c|c|c|c|c|}
\hline Product categories & Visiting sessions & \multicolumn{2}{|c|}{ Pageviews } & \multicolumn{2}{c|}{ Duration } \\
\hline & & Mean & Standard deviation & Mean & Standard deviation \\
\hline Search goods & 26,141 & 35.0 & 27.8 & 29.3 & 28.9 \\
\hline Experience goods & 1,387 & 40.8 & 29.3 & 32.3 & 25.6 \\
\hline Total & 27,528 & 35.3 & 27.9 & 29.5 & 28.8 \\
\hline
\end{tabular}


Table 3: Descriptive statistics of pageviews and duration categorized by purchase outcomes and websites

\begin{tabular}{|c|c|c|c|c|c|}
\hline Purchase outcomes & Visiting sessions & \multicolumn{2}{|c|}{ Pageviews } & \multicolumn{2}{c|}{ Duration } \\
\hline & & Mean & Standard deviation & Mean & Standard deviation \\
\hline Completed & & & & & \\
\hline Amazon & 24,509 & 35.0 & 27.8 & 29.4 & 29.0 \\
\hline Drugstore & 219 & 27.2 & 26.4 & 23.0 & 27.2 \\
\hline Ticketmaster & 418 & 23.4 & 14.4 & 29.8 & 29.6 \\
\hline Landsend & 216 & 43.6 & 32.4 & 24.7 & 20.3 \\
\hline VictoriasSecret & 969 & 39.5 & 27.7 & 35.6 & 26.9 \\
\hline Total & 26,331 & 35.1 & 27.8 & 29.4 & 28.9 \\
\hline Not completed & & & & & \\
\hline Amazon & 1,197 & 39.6 & 28.9 & 29.8 & 28.0 \\
\hline Total & 1,197 & 39.6 & 28.9 & 29.8 & 28.0 \\
\hline
\end{tabular}

Table 4: Descriptive statistics of pageviews and duration categorized by product categories and websites

\begin{tabular}{|c|c|c|c|c|c|}
\hline Product categories & Visiting sessions & \multicolumn{2}{|c|}{ Pageviews } & \multicolumn{2}{|c|}{ Duration } \\
\hline & & Mean & Standard deviation & Mean & Standard deviation \\
\hline Search goods & & & & & \\
\hline Amazon & 25,706 & 35.2 & 27.8 & 29.4 & 29.0 \\
\hline Drugstore & 219 & 27.2 & 26.4 & 23.0 & 27.2 \\
\hline Ticketmaster & 216 & 23.4 & 14.4 & 29.8 & 29.6 \\
\hline Total & 26,141 & 35.0 & 27.8 & 29.3 & 28.9 \\
\hline Experience goods & & & & & \\
\hline Landsend & 418 & 43.6 & 32.4 & 24.7 & 20.3 \\
\hline VictoriasSecret & 969 & 39.5 & 27.7 & 35.6 & 26.9 \\
\hline Total & 1,387 & 40.8 & 29.3 & 32.3 & 25.6 \\
\hline
\end{tabular}

To verify the correlation between the pageview and the visit duration, we report the Pearson's r-coefficient of 0.720 with the $p$-value of .000 . We further inspect the quality of the correlation coefficient by dividing the data set into multiple small groups and observing the coefficients between the pageview and the visit duration across the groups. Should the correlation coefficients be found consistently across the groups, the value of 0.720 that we discovered is considered valid.

As shown in Table 5, all coefficients we calculated and tested across small groups of data categorized by purchase outcome, product categories, or participating websites are consistent to the coefficient we discovered from the analysis of the entire data set. It thus implies valid finding on the correlation between the pageview and the visit duration.

For further exploration, we analyzed the correlation between the purchase outcomes and the product categories using the Chi-square test. The statistics of 66.398 and the $p=v a l u e$ of .000 validated the significant association between the purchase outcomes and the product categories. Given the nominal scale of the purchase outcome and the product categories, it is acceptable only to confirm whether the two variables are related. It is however improper to discuss the direction or the magnitude of the relationship (Hair, 2013). 
Table 5: Correlation coefficients between the pageview and the visit duration, calculated based on the entire data set, or based on small sets of data categorized by purchase outcome, product categories, and participating websites

\begin{tabular}{|l|c|c|}
\hline \multicolumn{1}{|c|}{ Scope of data } & Sessions & $\begin{array}{c}\text { Pearson's r coefficients between } \\
\text { the pageview and the visit } \\
\text { duration* }\end{array}$ \\
\hline Entire data set & 27,528 & .720 \\
\hline Data categorized by purchase horizon & & .721 \\
\hline Completed & 26,331 & .701 \\
\hline Not Completed & 1,197 & .722 \\
\hline Data categorized by product categories & & .698 \\
\hline Search goods & 26,141 & \\
\hline Experience goods & 1,387 & .723 \\
\hline Data categorized by participating websites & & .789 \\
\hline Amazon & 25,706 & .608 \\
\hline Drugstore & 219 & .647 \\
\hline Ticketmaster & 216 & .771 \\
\hline Landsend & 418 & \\
\hline VictoriasSecret & 969 & \\
\hline
\end{tabular}

${ }^{*}$ All coefficients are significant at 0.05 .

\section{Conclusions}

The present study extracts a large set of data from the panel clickstream service ComScore. After cleansing it, we had 27,528 visit sessions from five online retail websites. About $96 \%$ of the collected sessions resulted in a purchase. This high conversion could perhaps be a result of the selection of well-accepted e-commerce websites, one of which is Amazon (Verheijden, 2012; Olbrich \& Holsing, 2011). The visitors of the collected sessions viewed an average of 35.3 webpages and spent about 29.5 minutes per session. Compared to previous findings in which Mallapragada, et al., (2014) reported the previews of 20.1 pages and the duration of 20.2 minutes, and Olbrich \& Holsing (2011) stated an average duration of only 17.3 minutes, the visitors in our study appeared to observe many pages and to have relatively long sessions. Based on Moe's (2003) typology of online customers, the visitors in our study seem to resemble those in search of a large amount of information for future purchase. Moe (2003) labeled those customers as the searchers.

Our first two hypotheses $(\mathrm{H} 1$ and $\mathrm{H} 2)$ tested if the number of pageviews and the length of visit duration between the sessions with and those without the purchase are significant. The result of the former is statistically significant but that of the latter is not. A look at our data indicates that the pageviews in the sessions with the purchase are less than those in the sessions with no purchase. However, the amounts of visit duration in both sessions are about the same. It implies that the visitors who ultimately made an online purchase would view fewer numbers of web pages than those visitors who have not decided to buy any item but the length of their visits to the websites are not different. Such findings are consistent to what was reported in previous work. Referring to the searcher by Moe (2003), the customers who make a purchase appear to view a fewer number of pages than those who prefer to gather only information and delay the purchase. Nonetheless, these two groups of customers may spend a comparable amount of time visiting the retail websites. The relative significance of pageviews as compared to the visit duration is also recognized by Lin, et al. (2010). Their analysis suggested that the pageview is more indicative of the purchase than the visit duration since the pageview is not affected by the visitor's browsing pace or their other habits, as compared to visit duration (p. 134). This could explain the trivial difference of visit duration between the sessions with and without purchase. Using a multivariate Tobit equation, Mallapragada, et al. (2016) confirmed the equally significant effects of both pageviews and visit duration on whether online purchases were made. Such inconsistent findings may however urge fellow researchers to continue this line of research.

We tested in $\mathrm{H} 3$ and $\mathrm{H} 4$ whether the pageview and the visit duration between the websites that offer search and experience goods are statistically significant and the test results confirm it is. The data in Table 2 point 
out that the visitors of the websites selling search items view more pages and stay longer than those in the websites offering experience items. The explanation for such findings is from the characteristics of both product categories. Given the sufficient amount of information on websites, customers would view few pages within a short stay in the websites that offer search goods including texts at Amazon or concert tickets at Ticketmaster. On the contrary, experience goods are difficult for the target to assess the product quality using only the detail available in the websites. This difficulty leads them to review more pages and perhaps presents a need to stay longer on the websites. Lin, et al's (2010) work has addressed both product categories and visiting behavior in online retail websites. Our findings are in line with theirs. In fact, Lin, et al. (2010) further remarked on the possible moderating effect of product categories on the relationship between visiting behavior and the purchase (p. 135). This may imply future research in the field of electronic commerce.

An analytic result of $\mathrm{H} 5$ testing serves as empirical validation of the positive significant relationship between the pageview and the visit duration. According to the findings, the more webpages the visitors have viewed, the longer their visit would be, or vice versa. Although in line with research remark in previous work (Mallapragada, et al., 2016; Olbrich \& Holsing, 2011; Lin, et al., 2010), this finding is our unique empirical contribution to confirm actual relationship between the pageview and the visit duration.

The result of our final exploration confirmed the significant association between the product categories and the purchase outcome in terms of the number of online sessions. It implies that visitors to some product websites may be more likely to make a purchase than those to the others. This finding may not be a surprise. It however adds to a body of empirical evidence in the area of online retail business (Mallapragada, et al., 2016; Sunikka, et al., 2011).

Our findings offer both theoretical and practical contributions. Theoretically, our findings have extended insight into the online retail customer's stickiness behavior (i.e., pageview and visit duration), product categories, and purchase outcomes using clickstream data from ComScore. Using such data has proved to be a valid technique to gain understanding into actual visiting behavior on electronic commerce websites, especially in the era of big data. Analytic results of the hypothesis testing add to the body of knowledge (Lin, et al., 2010; Verheijden, 2012; Moe, 2003; Mallapragada, et al., 2016) as empirical evidence that has validated the relationships among online retail website's visiting behavior in conjunction with product categories and purchase choices.

Practically, our findings could offer three recommendations for online practitioners. First, visitors of online retail websites in the present study who had made a purchase appeared to view fewer web pages but with a comparable length of stay, as compared to those who delayed the purchase. That is, customers spent a longer time per page than non-customers. As a result, website designers may need to consider content that could engage visitors long enough that they ultimately make a purchase. This recommendation is particularly valid for a target of search goods such as music, texts or vitamin supplement.

Second, visitors of websites selling experience goods including clothes or working outfits in the present study tend to view more pages and stay in the websites longer than those who visit the websites vending search goods. It is typical for a long duration of website stay with the high number of pages viewed, given the experience goods. Nonetheless, online retailers may be aware of this empirical evidence and try their best to provide the right amount of detail on the websites so the target of a given product category would make a buying decision. Finally, the increasing number of online purchases or the high conversion rate in the present study, as compared to the previous work, may ascertain the rise of online retail business and persuade practitioners to take part in the web-based commercial platform.

Like other research projects, this recent investigation has two limitations. First, the online trend is dynamically evolving extremely fast. What is feasible one day may be impossible the next day. Second, the collected data, although portraying actual web-based behavior, is simply a snapshot of what has happened online. The two limitations call for a continuous attempt of empirical examination into this phenomenon.

\section{Acknowledgement}

We are thankful for financial support, in part, from the "Chulalongkorn Academic Advancement into Its Second Century" project. 


\section{References}

Baird, N. (2017). Five Predictions For Retail in 2017. Available at https://www.forbes.com/ sites/nikkibaird/2017/01/04/five-predictions-for-retail-in-2017/\#692da78d4882 Accessed on March 28, 2017.

Bucklin, R., Lattin, J., Ansari, A., Gupta, S., Bell, D., Coupey, E. Little, J. Mela, C., Montgomery, A. \& Steckel, J. (2002). Choice and the Internet: From Clickstream to Research Stream, Marketing Letters, 13(3), 245-258.

Claase, M. (2014). Why Do Users Bond with Online Services?: A Literature Review on The Conceptualization of Online User Bonding in the Context of Online Services. Unpublished master Thesis. University of Twente. Available at http://essay.utwente.nl/65432/1/Claase_MA_Behavioural_Management_ and_Social_Sciences.pdf. Accessed on March 28, 2017

Danaher, P. J. (2007). Modeling page views across multiple websites with an application to Internet reach and frequency prediction, Marketing Science, 26(3), 422-437. DOI: 10.1287/mksc.I060.022.

Danaher, P., Mallarkey, G., \& Essegaier, S. (2006). Affecting web site visit duration: A cross-domain analysis, Journal of Marketing Research, 43(2), 182-194.

Gustafson, K. (2017). Retailers brace for 2017: Expect More Store Closings and Major Changes under Trump's Tax Policy. Available at http://www.cnbc.com/2016/12/27/retail-predictions-for-2017.html Accessed on March 28, 2017.

Hair, J. F. (2013). Essentials of marketing research, $3^{\text {rd }}$ edition, NY: McGraw-Hill.

Huang, L., Jia, L., \& Song, J. (2015). Antecedents of User Stickiness and Loyalty and Their Effects on Users' Group-Buying Repurchase Intention. Available at http://aisel.aisnet.org/amcis2015/e-Biz/ GeneralPresentations/ 1/ Accessed on March 28, 2017.

Kim, S., Baek, T., Kim, Y.-K., \& Yoo, K. (2016). Factors Affecting Stickiness and Word of Mouth in Mobile Applications, Journal of Research in Interactive Marketing, 10(3),177-192. https://doi.org/10.1108/JRIM-06-2015-0046.

Kousha, K., \& Thelwall, M. (2016). Can Amazon. com reviews help to assess the wider impacts of books?. Journal of the Association for Information Science and Technology, 67(3), 566-581. DOI: 10.1002/asi.23404.

Lin, J. (2007). Online Stickiness: Its Antecedents and Effect on Purchasing Intention. Behaviour \& Information Technology, 26(6), 507-516. http://dx.doi.org/10.1080/01449290600740843.

Lin, L., Hu, P. J. H., Sheng, O. R. L., \& Lee, J. (2010). Is stickiness profitable for electronic retailers?. Communications of the ACM, 53(3), 132-136. DOI: 10.1145/1666420.1666454

Mallapragada , G., Chandukala, S. R., \& Liu, Q. (2016). Exploring the Effects of "What" (Product) and "Where" (Website) Characteristics on Online Shopping Behavior. Journal of Marketing, 80(2), 2138. http://dx.doi.org/10.1509/jm.15.0138.

Moe, W. W. (2003). Buying, Searching, or Browsing: Differentiating Between Online Shoppers Using In-Store Navigational Clickstream. Journal of Consumer Psychology, 13(1\&2), 29-39. https://doi.org/10.1207/S15327663JCP13-1\&2_03.

Moe, W. W. \& Fader, P. S. (2004). Dynamic Conversion Behavior at E-Commerce Sites. Management Science, 50(3), 326-335. https://doi.org/10.1287/mnsc.1040.0153.

Montgomery, A. L., Li, S., Srinivasan, K., \& Liechty, J. C. (2004). Modeling Online Browsing and Path Analysis Using Clickstream Data. Marketing Science, 23(4), 579-595. https://doi.org/10.1287/mksc.1040.0073. 
Okada, K. \& Takahashi, H. (2015). Page View-Based Investor Attention and IPO Pricing. Unpublished manuscript. Available online at http://sfm.finance.nsysu.edu.tw/php/Papers/ CompletePaper/066279035158.pdf. Accessed on March 28, 2017.

Olbrich, R. \& Holsing, C. (2011). Modeling Customer Purchasing Behavior in Social Shopping Communities with Clickstream Data. International Journal of Electronic Commerce, 16(2), 15-40. http://dx.doi.org/10.2753/JEC1086-4415160202.

Panagiotelis, A., Smith, M., \& Danaher, P. (2014). From Amazon to Apple: Modeling Online Retail Sales, Purchase Incidence, and Visit Behavior, Journal of Business \& Economic Statistics, 32(1), 14-29. http://dx.doi.org/10.1080/07350015.2013.835729.

Roy, S., Lassar, W., \& T. Butaney, G. (2014). The Mediating Impact of Stickiness and Loyalty on Word-ofMouth Promotion of Retail Websites: A Consumer Perspective. European Journal of Marketing, 48(9/10), 1828-1849. https://doi.org/10.1108/EJM-04-2013-0193.

Similarweb (2016). Amazon Analytics. Available at https://www.similarweb.com/website/ amazon.com Accessed on March 28, 2017.

Sunikka, A., Bragge, J., \& Kallio, H. (2011). The Effectiveness of Personalized Marketing in Online Banking: A Comparison between Search and Experience Offerings. Journal of Financial Services Marketing, 16(3-4), 183-194. https://doi.org/10.1057/fsm.2011.24.

Verheijden, R. (2012). Predicting purchasing behavior throughout the clickstream. Unpublished master thesis, Master of Science in Innovation Sciences, Eindhoven University of Technology.

Xun, J. (2015). Return on Web Site Visit Duration: Applying Web Analytics Data. Journal of Direct, Data and Digital Marketing Practice, 17(1), 54-70. https://doi.org/10.1057/dddmp.2015.33.

Yan, L., \& Li, Chunping. (2006). Incorporating Pageview Weight into an Association-Rule-Based Web Recommendation System. in Australasian Joint Conference on Artificial Intelligence. Springer Berlin Heidelberg, 577-586. 